Military Technical College

Kobry Elkobbah,

Cairo, Egypt

May $29-31,2012$

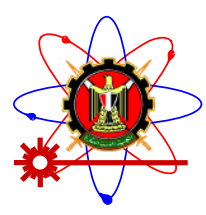

$6^{\text {th }}$ International Conference

on Mathematics and

Engineering Physics

(ICMEP-6)

\title{
Interactive TOPSIS algorithms for solving multi-level non-linear multi-objective decision-making problems
}

\author{
Ibrahim A. Baky ${ }^{\text {a, * }}$ \\ ${ }^{a}$ Department of Basic Sciences, Faculty of Engineering, Benha University, EL-Qalyoubia - Egypt
}

\begin{abstract}
This paper extended the concept of the technique for order preference by similarity to ideal solution (TOPSIS) to develop a methodology for solving multi-level non-linear multiobjective decision-making (MLN-MODM) problems. Also, two new interactive algorithms are presented for the proposed TOPSIS approach for solving these types of mathematical programming problems. The first proposed interactive TOPSIS algorithm includes the membership functions of the decision variables for each level except the lower level of the multilevel problem. These satisfactory decisions are evaluated separately by solving the corresponding single-level MODM problems. The second proposed interactive TOPSIS algorithm lexicographically solves the MODM problems of the MLN-MOLP problem by taking into consideration the decisions of the MODM problems for the upper levels. Illustrative example is presented in order to show the efficiency and superiority of the proposed approach and the two interactive TOPSIS algorithms.
\end{abstract}

Keywords: Multiple objective programming, Multi-level Programming, TOPSIS, Fuzzy Programming

\section{Introduction}

Hierarchical optimization or multi-level programming (MLP) techniques are extensions of Stackleberg games for solving decentralized planning problems with multiple decision makers (DMs) in a hierarchical organization where each unit seeks its own interests. The basic concept of the multi-level programming technique is that the first-level decision maker (FLDM) sets his/her goal and/or decision, and then asks each subordinate level of the organization for their optima, that calculated in isolation. The lower level decision makers' decisions are then submitted and modified by the FLDM in consideration of the overall benefit for the organization. The process continues until a satisfactory solution is reached (for more details see (Ayed, 1993; Bialas and Karwan, 1984; Lee and Shih, 2001; Osman et al ., 2003; Osman et al ., 2004; Pramanik and Roy, 2006; Sinha, 2003). Traditional approaches include vertex enumeration algorithms, approaches based on KKT conditions and penalty functions (Lai, 1996). The use of the fuzzy set theory (Zadeh, 1965) for decision problems with several conflicting objectives was first introduced by Zimmermann, 1978. Thereafter, various versions of fuzzy programming (FP) have been investigated and widely circulated in literature (Luhandjula, 1984; Mohamed, 1997; Lee and Shih, 2001; Moitra, and Pal, 2002; Osman et al ., 2003; Osman et al ., 2004; Baky, 2010). The use of the concept of membership function of fuzzy set theory to multi-level programming problems for satisfactory decisions was first introduced by Lai (1996). Then, Lai's satisfactory solution concept was extended by Shih et al. (1996) and a supervised search procedure with the use of max-min operator of Bellman and Zadeh (1970) was proposed. Abo-Sinna (2001) and 


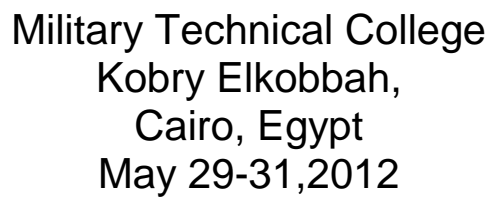

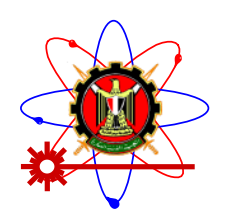

Osman et al. (2004) extended the fuzzy approach for multi-level programming problems of Shih et al. (1996) to solve bi-level and three-level non-linear multi-objective programming problems. Another multi-level multi-objective programming approaches are presented by Osman et al. 2003; Abo-Sinna and Baky (2007); Baky, 2010. A bibliography of the related references on multi-level programming in both linear and non-linear cases, which is updated biannually, can be found in Vicent and Calamai (1994).

Technique for order preference by similarity to ideal solution (TOPSIS), one of the known classical multiple criteria decision making (MCDM) method, bases upon the concept that the chosen alternative should have the shortest distance from the positive ideal solution (PIS) and the farthest from the negative ideal solution (NIS). It was first developed by Hwang and Yoon (1981) for solving a multiple attribute decision making problem. A similar concept has also been pointed out by Zeleny (1982). Lai et al. (1994) extended the concept of TOPSIS to develop a methodology for solving multiple objective decision making (MODM) problems. Recently, AboSinna (2000) extended TOPSIS approach to solve multi-objective dynamics programming (MODP) problems. He shows, that using the fuzzy max-min operator with non-linear membership functions, the obtained solutions are always non-dominated solutions of the original MODP problems. A further extensions of TOPSIS for large scale multi-objective non-linear programming problems with block angular structure was presented by Abo-Sinna and Amer (2000) and Abo-Sinna et al. (2008). Deng et al. (2000) formulated the inter-company comparison process as a multi-criteria analysis model, and presented an effective approach by modifying TOPSIS for solving such a problem. Chen (2000) extended the concept of TOPSIS to develop a methodology for solving multi-person multi-criteria decision-making problems in a fuzzy environment and he defined the fuzzy positive ideal solution (FPIS) and the fuzzy negative ideal solution (FNIS).

Generally, TOPSIS provides a broader principle of compromise for solving multiple criteria decision making problems. It transfers m-objectives (criteria), which are conflicting and noncommensurable, into two objectives (the shortest distance from the PIS and the longest distance from the NIS). They are commensurable and most of time conflicting. Then, the biobjective problem can be solved by using membership functions of fuzzy set theory to represent the satisfaction level for both criteria and obtain TOPSIS's compromise solution by a secondorder compromise operation. The max-min operator is then considered as a suitable one to resolve the conflict between the new criteria (the shortest distance from the PIS and the longest distance from the NIS) (Lai et al., 1994; Abo-Sinna and Amer, 2000); Abo-Sinna et al. (2008)).

In this paper, we further extended the concept of TOPSIS to develop a methodology for solving multi-level non-linear multi-objective decision-making (MLN-MODM) problems of maximization-type. Two interactive TOPSIS algorithms are presented for the proposed TOPSIS approach for solving MLN-MODM problems. The remainder of this paper is organized as follows. Section 2 presents the formulation of multi-level non-linear multi-objective decisionmaking problems. Section 3 discusses briefly the basic concepts of distance measures of "closeness" and its normalization. The proposed TOPSIS approach is developed in section 4 for solving MLN-MODM problems. Also in this section, the algorithmic steps of the TOPSIS 


\section{Military Technical College Kobry Elkobbah, Cairo, Egypt May $29-31,2012$}

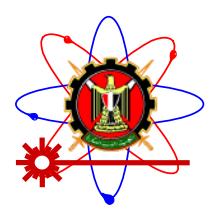

$6^{\text {th }}$ International Conference on Mathematics and Engineering Physics

(ICMEP-6)

approach for solving single-level MODM problems of Lia et. al. (1994) is proposed. Section 5 presents the two interactive algorithm of the proposed TOPSIS approach for solving MLNMODM problems. The next section presents an illustrative numerical example in order to show the efficiency and superiority of the proposed approach and the two interactive TOPSIS algorithms. Finally, the concluding remarks are made in Section 7.

\section{Problem Formulation}

Consider a $q$-level programming problem of maximization-type nonlinear multi-objective functions at each level. Let $\mathrm{DM}_{k}$ denote the decision maker at the $k^{\text {th }}$ level that has control over the decision variable $\boldsymbol{x}_{k}=\left(x_{k 1}, x_{k 2}, \ldots, x_{k n_{k}}\right) \in \mathrm{R}^{n_{k}}, k=1,2, \ldots, q$, where $\boldsymbol{x}=\left(\boldsymbol{x}_{1}, \boldsymbol{x}_{2}, \ldots, \boldsymbol{x}_{k}\right) \in \mathrm{R}^{n}$ and $n=n_{1}+n_{2}+\ldots+n_{q}$ and furthermore assume that:

$$
\mathrm{F}_{k}\left(\boldsymbol{x}_{1}, \boldsymbol{x}_{2}, \ldots, \boldsymbol{x}_{q}\right) \equiv \mathrm{F}_{k}(\boldsymbol{x}): \mathrm{R}^{\mathrm{n}_{1}} \times \mathrm{R}^{\mathrm{n}_{2}} \times \ldots \times \mathrm{R}^{\mathrm{n}_{q}} \rightarrow \mathrm{R}^{\mathrm{m}_{k}}, k=1,2, \ldots, q
$$

are the vector of objective functions to the $\mathrm{DM}_{k}, k=1,2, \ldots, q$ Mathematically, the MLNMODM problems of maximization-type may be formulated as follows (Osman et al ., 2004; AboSinna and Baky, 2007; Baky, 2010):

[1 $1^{\text {st }}$ Level $]$

$$
\operatorname{Max}_{x_{l}} F_{1}(\boldsymbol{x})=\operatorname{Max}_{x_{l}}\left(f_{11}(\boldsymbol{x}), f_{12}(\boldsymbol{x}), \ldots, f_{1 \mathrm{~m}_{l}}(\boldsymbol{x})\right)
$$

where $\boldsymbol{x}_{2}, \boldsymbol{x}_{3}, \ldots, \boldsymbol{x}_{p}$ solves

$\left[2^{\text {nd }}\right.$ Level $]$

$$
\operatorname{Max}_{x_{2}} F_{2}(\boldsymbol{x})=\operatorname{Max}_{x_{2}}\left(f_{21}(\boldsymbol{x}), f_{22}(\boldsymbol{x}), \ldots, f_{2 \mathrm{~m}_{2}}(\boldsymbol{x})\right)
$$

where $\boldsymbol{x}_{p}$ solves

$\left[q^{\text {th }}\right.$ Level $]$

$$
\operatorname{Max}_{x_{q}} F_{q}(\boldsymbol{x})=\operatorname{Min}_{x_{q}}\left(f_{q 1}(\boldsymbol{x}), f_{q 2}(\boldsymbol{x}), \ldots, f_{q \mathrm{~m}_{q}}(\boldsymbol{x})\right)
$$

subject to

$$
\boldsymbol{x} \in \boldsymbol{G}=\left\{\boldsymbol{x} \in \mathrm{R}^{\mathrm{n}} \mid g_{i}(\boldsymbol{x}) \leq 0, i=1,2, \ldots, s\right\} \neq \phi
$$

where $\boldsymbol{G}$ is the multi-level convex constraints feasible choice set, , $m_{k}, k=1,2, \ldots, q$, are the number of $\mathrm{DM}_{k}$ 's objective functions and $s$ is the number of the constraints.

\section{Some Basic Concepts of distance Measures}

This section briefly surveys some basic concepts of distance Measures, for more details see: 

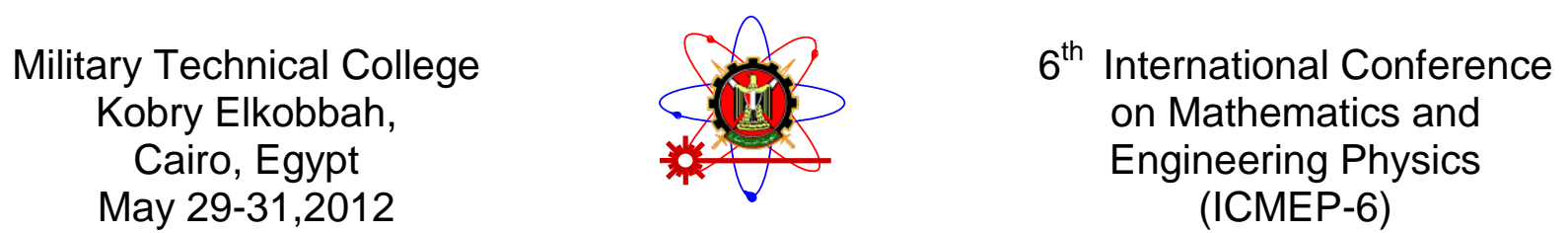

Yu and Zeleny, 1975; Lai et al., 1994; Abo-Sinna and Amer, 2000; Abo-Sinna, 2001; Abo-Sinna et al., 2008. Consider the vector of objective functions $F(\boldsymbol{x})=\left(f_{1}(\boldsymbol{x}), f_{2}(\boldsymbol{x}), \ldots, f_{\mathrm{m}}(\boldsymbol{x})\right)$ and the ideal vector of objective functions $F^{*}=\left(f_{1}^{*}, f_{2}^{*}, \ldots, f_{m}^{*}\right)$ (ideal point- reference point- positive ideal solution (PIS)) in the m-objective space. And consider the vector of anti-ideal solution of objective functions $F^{-}=\left(f_{1}^{-}, f_{2}^{-}, \ldots, f_{m}^{-}\right)$(anti-ideal point - nadir point - negative ideal solution (NIS)). Where $f_{j}^{*}=\max _{x \in \mathrm{G}} f_{j}(\boldsymbol{x})$ and $f_{j}^{-}=\min _{x \in \mathrm{G}} f_{j}(\boldsymbol{x}), j=1,2, \ldots, m$. As the measure of "closeness", $L_{P}$-metric is used. The $L_{P}$-metric defines the distance between two points $F(\boldsymbol{x})$ and $F^{*}$ as:

$$
d_{p}=\left\{\sum_{j=1}^{m} \lambda_{j}^{p}\left[f_{j}^{*}-f_{j}(\boldsymbol{x})\right]^{p}\right\}^{\frac{1}{p}}, p=1,2, \ldots, \infty
$$

where $\lambda_{j}, j=1, \ldots, \mathrm{m}$ are the relative importance (weights) of objectives. If the objective functions $f_{j}(\boldsymbol{x}), j=1, \ldots, \mathrm{m}$ are not expressed in commensurable units, then a scaling function for every objective functions, usually, this dimensionless is the interval $[0,1]$. In this case, the following metric could be used:

$$
d_{p}=\left\{\sum_{j=1}^{m} \lambda_{j}^{p}\left[\frac{f_{j}^{*}-f_{j}(\boldsymbol{x})}{f_{j}^{*}-f_{j}^{-}}\right]^{p}\right\}^{\frac{1}{p}}, p=1,2, \ldots, \infty
$$

To obtain a compromise solution of MODM problems of the form :

$$
\begin{aligned}
& \max \quad F(\boldsymbol{x})=\left(f_{1}(\boldsymbol{x}), f_{2}(\boldsymbol{x}), \ldots, f_{\mathrm{m}}(\boldsymbol{x})\right) \\
& \text { subject to } \boldsymbol{x} \in \boldsymbol{G}=\left\{\boldsymbol{x} \in \mathrm{R}^{\mathrm{n}} \mid g_{i}(\boldsymbol{x}) \leq 0, i=1,2, \ldots, s\right\} \neq \phi
\end{aligned}
$$

The global criterion method, goal programming, fuzzy programming, and interactive approaches use the distance family of (2) and (3) when the ideal vector of objective functions $F^{*}=\left(f_{1}^{*}, f_{2}^{*}, \ldots, f_{m}^{*}\right)$ being the reference point. The problem becomes how to solve the following auxiliary problem (Lai et al., 1994):

$$
\min _{\boldsymbol{x} \in \mathbf{G}} d_{p}=\left\{\sum_{j=1}^{m} \lambda_{j}^{p}\left[\frac{f_{j}^{*}-f_{j}(\boldsymbol{x})}{f_{j}^{*}-f_{j}^{-}}\right]^{p}\right\}^{\frac{1}{p}}, p=1,2, \ldots, \infty
$$

The value chosen for $p$ reflects the way of achieving a compromise by minimize the weight sum of the divisions of objective from their respective reference point (ideal solution). The parameter $p$ plays the role of the "balancing factor" between the group utility and maximal individual regret; 


\section{Military Technical College Kobry Elkobbah, Cairo, Egypt May $29-31,2012$}
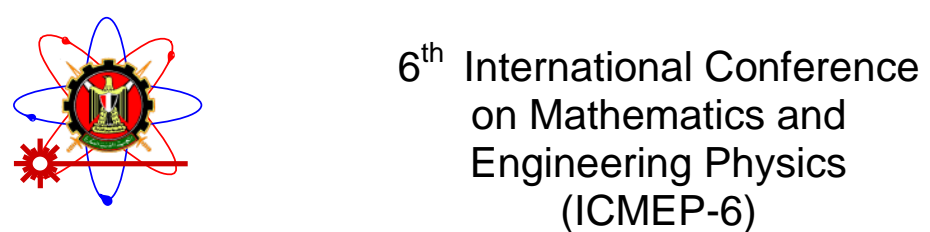

as $p$ increase, the group utility (distance $d_{P}$ ) decrease, i.e. $d_{1} \geq d_{2} \geq \ldots \geq d_{p}$ and greater emphasis is given to the largest deviation in forming the total. Specifically, $\mathrm{p}=1$ implies an equal importance (weights) for all these deviations, while $\mathrm{p}=2$ implies that these deviations are weighted proportionately with the largest deviation having the largest weight (Lai et al., 1994). Finally for $p=\infty$, the largest deviation completely dominates the distance determination, the $L_{\infty}$ - metric is of the form:

$$
d_{\infty}=\max _{j}\left\{\lambda_{j}\left[f_{j}^{*}-f_{j}(\boldsymbol{x})\right]\right\} \quad \text { or } \quad d_{\infty}=\max _{j}\left\{\lambda_{j}\left[\frac{f_{j}^{*}-f_{j}(\boldsymbol{x})}{f_{j}^{*}-f_{j}^{-}}\right]\right\}
$$

\section{TOPSIS for MLN-MODM Problems}

In most practical situations, we might like to have a decision, which not only makes as much profit as possible, but also avoids as much risk as possible. This concept has been developed by Hwang and Yoon (1981). They provided a new approach, TOPSIS, for solving a multiple attribute decision-making (MADM) problems. It is based upon the principle that the chosen alternative should have the shortest distance from the positive ideal solution (PIS) and the farthest form the negative ideal solution (NIS). Hwang and Yoon used both PIS $\left(F^{*}\right)$ and NIS $\left(F^{-}\right)$to normalize the distance family and obtain the form of distance family of equation (3). Lia et. al. (1994) extended the concept of TOPSIS to develop a methodology for solving multiple objective decision making (MODM) problems. In this paper, we further extended the concept of TOPSIS (Lai et al., 1994) for MLN-MODM problems.

\section{4-1 The TOPSIS approach for the upper MODM problems}

The TOPSIS approach of Lia et. al. (1994) is considered, in this paper, to solve the single-level MODM problems of the MLN-MODM problem (1) that has the following general form for the $k^{\text {th }}$-level MODM problem, $k=1,2, \ldots, q-1$ :

$$
\begin{aligned}
& \underset{x_{k}}{\operatorname{Max}_{k}} F_{k}(\boldsymbol{x})=\operatorname{Max}_{x_{k}}\left(f_{k 1}(\boldsymbol{x}), f_{k 2}(\boldsymbol{x}), \ldots, f_{k \mathrm{~m}_{k}}(\boldsymbol{x})\right) \\
& \text { subject to } \\
& \qquad \boldsymbol{x} \in \boldsymbol{G}=\left\{\boldsymbol{x} \in \mathrm{R}^{\mathrm{n}} \mid g_{i}(\boldsymbol{x}) \leq 0, i=1,2, \ldots, s\right\} \neq \phi
\end{aligned}
$$

The TOPSIS model formulation of Lia et. al. approach can be briefly stated as following, (for more details see: Lai et al., 1994) :

$$
\begin{array}{ll}
\operatorname{Min} & d_{p}^{P I S^{k}}(\boldsymbol{x}) \\
\operatorname{Max} & d_{p}^{N I S^{k}}(\boldsymbol{x}) \\
& \text { Subject to } \\
& \boldsymbol{x} \in \boldsymbol{G}=\left\{\boldsymbol{x} \in \mathrm{R}^{\mathrm{n}} \mid g_{i}(\boldsymbol{x}) \leq 0, i=1,2, \ldots, s\right\} \neq \phi
\end{array}
$$


Military Technical College

Kobry Elkobbah,

Cairo, Egypt

May $29-31,2012$ $6^{\text {th }}$ International Conference

on Mathematics and

Engineering Physics

(ICMEP-6)

where

$$
d_{p}^{P I S^{k}}(\boldsymbol{x})=\left\{\sum_{j=1}^{m_{k}} \lambda_{k j}^{p}\left[\frac{f_{k j}^{*}-f_{k j}(x)}{f_{k j}^{*}-f_{k j}^{-}}\right]^{p}\right\}^{1 / p} \text { and } d_{p}^{N I S^{k}}(\boldsymbol{x})=\left\{\sum_{j=1}^{m_{k}} \lambda_{k j}^{p}\left[\frac{f_{k j}(x)-f_{k j}^{-}}{f_{k j}^{*}-f_{k j}^{-}}\right]^{p}\right\}^{1 / p}
$$

and where $f_{k j}^{*}, f_{k j}^{-}$and $\lambda_{k j}, \mathrm{j}=1,2, \ldots, \mathrm{m}_{k}$ (the individual positive ideal solutions, the individual negative ideal solutions and the relative importance (weights) of objectives functions in $k^{\text {th }}$-level MODM problem, respectively) are defined as in section 3 . Let $F^{k^{*}}=\left(f_{k 1}^{*}, f_{k 2}^{*}, \ldots, f_{k m_{k}}^{*}\right)$ and $F^{k^{-}}=\left(f_{k 1}^{-}, f_{k 2}^{-}, \ldots, f_{k m_{k}}^{-}\right)$. Assume that the membership functions $\left(\mu_{k 1}(\boldsymbol{x})\right.$ and $\left.\mu_{k 2}(\boldsymbol{x})\right)$ of the two objective functions in (9) are linear between $\left(d_{p}^{k}\right)^{*}$ and $\left(d_{p}^{k}\right)^{-}$which are:

$$
\begin{aligned}
& \left(d_{p}^{P I S^{k}}\right)^{*}=\min _{x \in \mathrm{G}} d_{p}^{P I S^{k}}(\boldsymbol{x}) \text { and the solution is } \boldsymbol{x}^{k P}, \\
& \left(d_{p}^{N I S^{k}}\right)^{*}=\max _{x \in \mathrm{G}} d_{p}^{N I S^{k}}(\boldsymbol{x}) \text { and the solution is } \boldsymbol{x}^{k N}, \\
& \left(d_{p}^{P I S^{k}}\right)^{-}=d_{p}^{P I S^{k}}\left(\boldsymbol{x}^{k N}\right) \text { and }\left(d_{p}^{N I S^{k}}\right)^{-}=d_{p}^{N I S^{k}}\left(\boldsymbol{x}^{k P}\right) .
\end{aligned}
$$

Also, we propose, in this paper, that $\left(d_{p}^{P I S^{k}}\right)^{-}$and $\left(d_{p}^{N I S^{k}}\right)^{*}$ can be taken as $\left(d_{p}^{P I S^{k}}\right)^{-}=\max _{x \in \mathrm{G}} d_{p}^{P I S^{k}}(\boldsymbol{x}) \quad$ and $\quad\left(d_{p}^{N I S^{k}}\right)^{*}=\min _{x \in \mathrm{G}} d_{p}^{N I S^{k}}(\boldsymbol{x}), \quad$ respectively. $\quad$ Let $\mathrm{d}_{p}^{k^{*}}=\left(\left(d_{p}^{P I S^{k}}\right)^{*},\left(d_{p}^{N I S^{k}}\right)^{*}\right) \quad$ and $\quad \mathrm{d}_{p}^{k^{-}}=\left(\left(d_{p}^{P I S^{k}}\right)^{-},\left(d_{p}^{N I S^{k}}\right)^{-}\right)$. Thus $\quad \mu_{k l}(\boldsymbol{x}) \equiv \mu_{d_{p}^{P I S^{k}}}(\boldsymbol{x}) \quad$ and $\mu_{k 2}(\boldsymbol{x}) \equiv \mu_{d_{p}^{N I S^{k}}}(\boldsymbol{x})$ cab be obtained as (see: figure 1):

$$
\mu_{k 1}(\boldsymbol{x})= \begin{cases}1 & \text { if } \quad d_{p}^{P I S^{k}}(\boldsymbol{x})<\left(d_{p}^{P I S^{k}}\right)^{*} \\ 1-\frac{d_{p}^{P I S^{k}}(\boldsymbol{x})-\left(d_{p}^{P I S^{k}}\right)^{*}}{\left(d_{p}^{P I S^{k}}\right)^{-}-\left(d_{p}^{P I S^{k}}\right)^{*}} & \text { if } \quad\left(d_{p}^{P I S^{k}}\right)^{*} \leq d_{p}^{P I S^{k}}(\boldsymbol{x}) \leq\left(d_{p}^{P I S^{k}}\right)^{-} \\ 0 & \text { if } \quad\left(d_{p}^{P I S^{k}}\right)^{-}<d_{p}^{P I S^{k}}(\boldsymbol{x})\end{cases}
$$


Military Technical College

Kobry Elkobbah,

Cairo, Egypt

May $29-31,2012$

$$
\mu_{k 2}(x)=\left\{\begin{array}{lcc}
1 & \text { if } & d_{p}^{N I S^{k}}(\boldsymbol{x}) \leq\left(d_{p}^{N I S^{k}}\right)^{*} \\
1-\frac{\left(d_{p}^{N I S^{k}}\right)^{*}-d_{p}^{N I S^{k}}(\boldsymbol{x})}{\left(d_{p}^{N I S^{k}}\right)^{*}-\left(d_{p}^{N I S^{k}}\right)^{-}} & \text {if } & \left(d_{p}^{N I S^{k}}\right)^{-} \leq d_{p}^{N I S^{k}}(\boldsymbol{x}) \leq\left(d_{p}^{N I S^{k}}\right)^{*} \\
0 & \text { if } & d_{p}^{N I S^{k}}(\boldsymbol{x})<\left(d_{p}^{N S^{k}}\right)^{-}
\end{array}\right.
$$

Applying the max-min decision model, which is proposed by Bellman and Zadeh (1970) and extended by Zimmermann (Zimmermann, 1978; Zimmermann, 1987), we can resolve (8) and obtaining the satisfying decision of the $k^{\text {th }}$-level MOLP problem, $x^{k^{*}}=\left(x_{1}^{k^{*}}, x_{2}^{k^{*}}, \ldots, x_{q}^{k^{*}}\right)$, by solving the following problem:

$$
\mu_{D}^{k}(\boldsymbol{x})=\max _{x \in G}\left\{\min \left(\mu_{k 1}(\boldsymbol{x}), \mu_{k 2}(\boldsymbol{x})\right)\right\}
$$

where $x_{j}^{k^{*}}=\left(x_{j 1}^{k^{*}}, x_{j 2}^{k^{*}}, \ldots, x_{j n_{j}}^{k^{*}}\right), j=1,2, \ldots, q$.

If $\alpha=\min \left(\mu_{k 1}(\boldsymbol{x}), \mu_{k 2}(\boldsymbol{x})\right)$, model (8) is equivalent to the form of Tchebycheff model (see: Lai and Hwang, 1992; Lai et al., 1994), which is equivalent to the following model:

$$
\begin{aligned}
& \max \alpha \\
& \text { subject to } \\
& \qquad \begin{array}{l}
\mu_{k 1}(\boldsymbol{x}) \geq \alpha \quad, \quad \mu_{k 2}(\boldsymbol{x}) \geq \alpha, \quad \alpha \in[0,1] \text { and } \\
\quad \boldsymbol{x} \in \boldsymbol{G}=\left\{\boldsymbol{x} \in \mathrm{R}^{\mathrm{n}} \mid g_{i}(\boldsymbol{x}) \leq 0, i=1,2, \ldots, s\right\} \neq \phi
\end{array}
\end{aligned}
$$

where $\alpha$ is the satisfactory level for both criteria of the shortest distance from the PIS and the farthest distance from the NIS. It is well known that if the optimal solution of (16) is the vector $\left(\alpha, x^{k^{*}}\right)$, then $x^{k^{*}}$ is the maximizing solution of model (8) and a satisfactory solution of the $k^{\text {th }}$-level MODM problem (Lai et al., 1994).

As discussed previously, the basic concept of the multi-level programming technique states that the first-level decision maker (FLDM) defines his/her objective functions and decisions with possible tolerances, which are described by membership functions of fuzzy set theory (Osman et al., 2003; Osman et al., 2004; Baky, 2010). This information is delivered to the second-level decision maker (SLDM) who solves his/her problem and defines its objective functions and decisions with possible tolerances in view of the FLDM. Then, the third-level decision maker (TLDM) solves his/her problem under restrictions of the FLDMs and SLDMs requirements. Afterwards, the TLDM presents his/her solution to the FLDM. If the FLDMs rejects this proposal, the FLDM must update and change former goals and decisions as well as 
Military Technical College

Kobry Elkobbah,

Cairo, Egypt

May $29-31,2012$ $6^{\text {th }}$ International Conference

on Mathematics and

Engineering Physics

(ICMEP-6)

their corresponding tolerances, also the SLDM must do the same until a satisfactory solution is reached. The process continues until the last level of the MLN-MODM problem (Osman et al., 2003; Osman et al., 2004; Baky, 2010).

According to this concept, let $t_{j}^{k_{L}}$ and $t_{j}^{k_{R}}, j=1,2, \ldots, n_{k}$ be the maximum acceptable negative and positive tolerances (relaxations) values on the decision vector controlled by $k^{t h}$-level MOLP problem, $x_{k}^{k^{*}}=\left(x_{k 1}^{k_{1}^{*}}, x_{k 2}^{k^{*}}, \ldots, x_{k n_{k}}^{k^{*}}\right)$. The tolerances $t_{j}^{k_{L}}$ and $t_{j}^{k}$ are not necessarily the same. The tolerances give the lower level decision makers an extended feasible region to search for the satisfactory solution. If the feasible region is empty, the negative and positive tolerances must be increased to give the lower level decision makers an extended feasible region to search for the satisfactory solution (Sinha, 2003; Osman et al ., 2004; Pramanik and Roy, 2006).

The linear membership functions (Figure 2) for each of the $n_{k}$ components of $x_{k}^{k^{*}}=\left(x_{k 1}^{k^{*}}, x_{k 2}^{k^{*}}, \ldots, x_{k n_{k}}^{k^{*}}\right)$ can be formulated as:

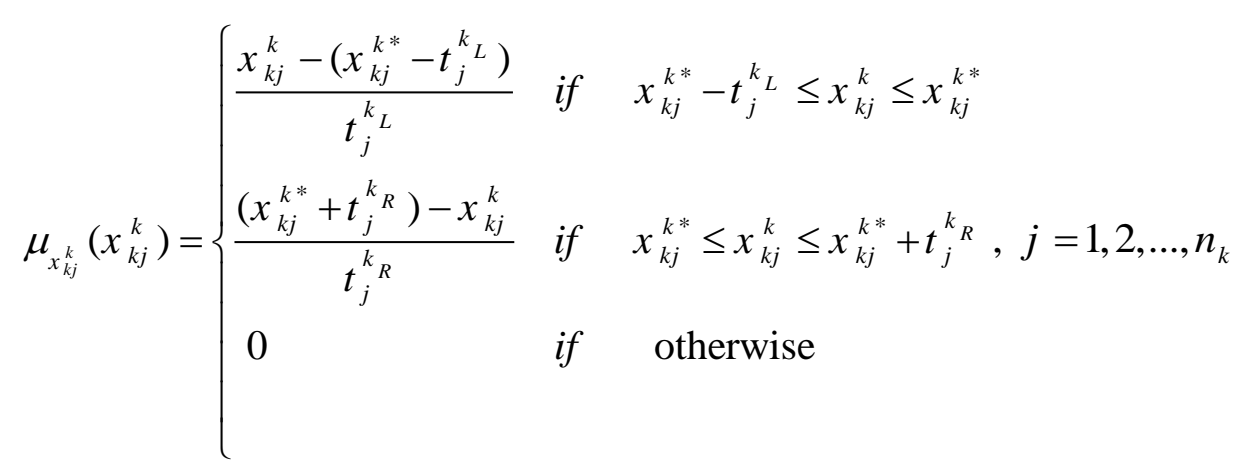

It may be noted that, the decision maker may desire to shift the range of $x_{k j}^{k}$. Following Pramanik and Roy, 2006 and Sinha, 2003, this shift can be achieved. 
Military Technical College

Kobry Elkobbah,

Cairo, Egypt

May $29-31,2012$ $6^{\text {th }}$ International Conference

on Mathematics and

Engineering Physics

(ICMEP-6)

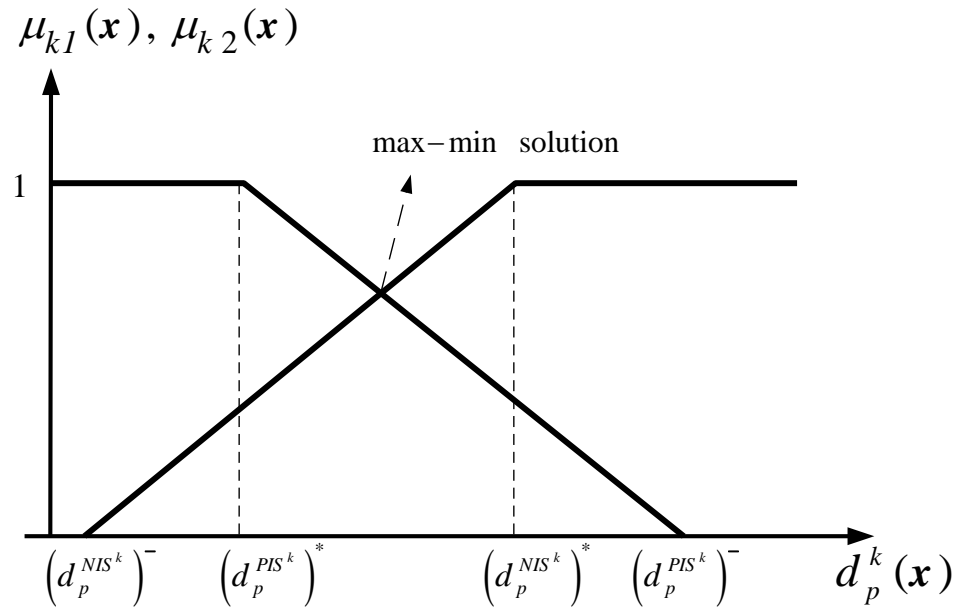

Figure 1. The membership functions of $\mu_{k 1}(\boldsymbol{x})$ and $\mu_{k 2}(\boldsymbol{x})$ (Lai et al., 1994)

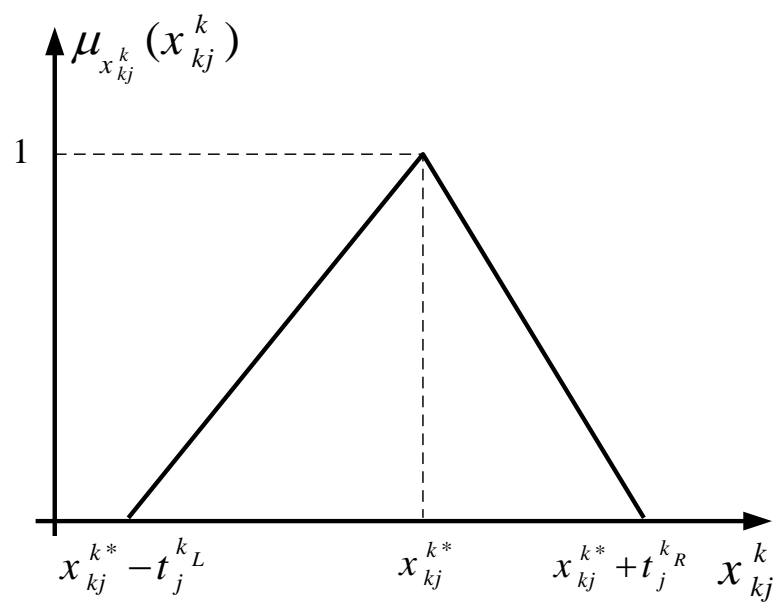

Figure 2. The Membership function of the decision variable $x_{k j}^{k}$

\section{The TOPSIS Algorithm for the upper MODM problems}

The algorithmic steps of the TOPSIS approach of Lia et. al. (1994) for solving a single-level MODM problems (in level $\mathbf{l}$ of MLN-MODM problems, $1=1,2, \ldots, q-1$ ) following Lia et. al. (1994) can be proposed, in this paper, as follows:

\section{Alg A:}

Step 1. Construct the PIS payoff table of the $\mathbf{I}^{\text {th }}$-level MODM problem (7) and obtain $F^{1^{*}}=\left(f_{11}^{*}, f_{12}^{*}, \ldots, f_{1 m_{1}}^{*}\right)$, the individual positive ideal solutions.

Step 2. Construct the NIS payoff table of the $\mathbf{I}^{\text {th }}$-level MODM problem (7) and obtain $F^{1^{-}}=\left(f_{11}^{-}, f_{12}^{-}, \ldots, f_{1 m_{1}}^{-}\right)$, the individual negative ideal solutions.

Step 3. Use Eq. (9) to construct $d_{p}^{P I S^{1}}(\boldsymbol{x})$ and $d_{p}^{N I S^{1}}(\boldsymbol{x})$.

Step 4. Ask the DM to select $p,\{p=1,2, \ldots, \infty\}$.

Step 5. Construct the payoff table of problem (8) and obtain $d_{p}^{1^{*}}$ and $d_{p}^{1^{-}}$.

Step 6. Elicit the membership functions $\mu_{d_{p}^{P I S}}(\boldsymbol{x})$ and $\mu_{d_{p}^{P I S^{u}}}(\boldsymbol{x})$.

Step 7. Formulate the Model (16) for the $\mathbf{I}^{\text {th }}$ - level MODM problem.

Step 8. Solve Model (16) to get $\boldsymbol{x}^{1^{*}}=\left(x_{1}^{1^{*}}, x_{2}^{1^{*}}, \ldots, x_{q}^{1^{*}}\right), x_{1}^{1^{*}}=\left(x_{11}^{1^{*}}, x_{12}^{1^{*}}, \ldots, x_{1 n_{1}}^{1^{*}}\right)$.

Step 9. Set the maximum negative and positive tolerances values on the decision vector $x_{1}^{1^{*}}=\left(x_{11}^{1^{*}}, x_{12}^{1^{*}}, \ldots, x_{1 n_{1}}^{1^{*}}\right), t_{j}^{1} L_{L}$ and $t_{j}^{1}{ }^{R}, j=1,2, \ldots, n_{\mathbf{1}}$.

Step 10. Return. 
Military Technical College

Kobry Elkobbah,

Cairo, Egypt

May 29-31,2012

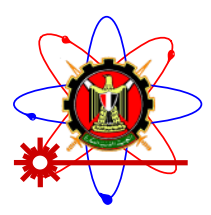

$6^{\text {th }}$ International Conference

on Mathematics and

Engineering Physics

(ICMEP-6)

\section{4-2 The Proposed TOPSIS approach for MLN-MODM problems}

In order to obtain a compromise solution (satisfactory solution) to the MLN-MODM problems using the TOPSIS approach, the distance family (3) to represent the distance function from the positive ideal solution $\left(d_{p}^{P I S^{M}}\right)$ and the distance function from the negative ideal solution $\left(d_{p}^{N I S^{M}}\right)$ can be proposed, in this paper, as the following new modified formulas of Hwang and Yoon (1981) and Lia et. al. (1994) for the objective functions of all levels of the MLN-MODM problems:

$$
\begin{aligned}
& d_{p}^{P I S^{M}}(\boldsymbol{x})=\left\{\sum_{i=1}^{q}\left(\sum_{j=1}^{m_{i}} \lambda_{i j}^{p}\left[\frac{f_{i j}^{*}-f_{i j}(\boldsymbol{x})}{f_{i j}^{*}-f_{i j}^{-}}\right]^{p}\right)\right\}^{1 / p} \\
& d_{p}^{N I S^{M}}(\boldsymbol{x})=\left\{\sum_{i=1}^{q}\left(\sum_{j=1}^{m_{i}} \lambda_{i j}^{p}\left[\frac{f_{i j}(\boldsymbol{x})-f_{i j}^{-}}{f_{i j}^{*}-f_{i j}-}\right]^{p}\right)\right\}^{1 / p}
\end{aligned}
$$

where $\lambda_{i j}, i=1,2, \ldots, q, j=1,2, \ldots, m_{i}$ are the relative importance (weights) of objectives of all levels, $f_{i j}^{*}=\max _{x \in \mathrm{G}} f_{i j}(\boldsymbol{x}), f_{i j}^{-}=\min _{x \in \mathrm{G}} f_{i j}(\boldsymbol{x}), i=1,2, \ldots, q, j=1,2, \ldots, m_{i}$, and $p=1,2, \ldots, \infty$. Let $F^{*}=\left(f_{11}^{*}, \ldots, f_{1 m_{1}}^{*}, f_{21}^{*}, \ldots, f_{2 m_{2}}^{*}, \ldots, f_{q 1}^{*}, \ldots, f_{q m_{q}}^{*}\right) \quad$ and $\quad F^{-}=\left(f_{11}^{-}, \ldots, f_{1 m_{1}}^{-}, f_{21}^{-}, \ldots, f_{2 m_{2}}^{-}, f_{q 1}^{-}, \ldots, f_{q m_{q}}^{-}\right) \quad$ the individual positive ideal solutions and individual negative ideal solutions for all levels, respectively . Similarly, for the special case of $p=\infty$, see (Lai and Hwang, 1992; Lia et. al., 1994) for the general form of the distance functions that can be applied to the proposed TOPSIS approach for solving MLN-MODM problems.

In order to obtain a compromise solution of the MLN-MODM problem, we transfer problem (1) into the following bi-objective problem with two commensurable (but often conflicting) objectives (Lia et. al., 1994; Abo-Sinna and Amer, 2000; Abo-Sinna, 2001; AboSinna et al., 2008):

$$
\begin{aligned}
& \operatorname{Min} d_{p}^{P I S^{M}}(\boldsymbol{x}) \\
& \operatorname{Max} d_{p}^{N I S^{M}}(\boldsymbol{x}) \\
& \text { subject to } \\
& \qquad \boldsymbol{x} \in \boldsymbol{G}=\left\{\boldsymbol{x} \in \mathrm{R}^{\mathrm{n}} \mid g_{i}(\boldsymbol{x}) \leq 0, i=1,2, \ldots, s\right\} \neq \phi
\end{aligned}
$$

where $p=1,2, \ldots, \infty$.

Since these two objectives are usual conflicting to each other, it is possible to simultaneously obtain their individual optima. Thus, we can use membership functions to represent these 
Military Technical College

Kobry Elkobbah,

Cairo, Egypt

May $29-31,2012$ $6^{\text {th }}$ International Conference

on Mathematics and

Engineering Physics

(ICMEP-6)

individual optima. Assume that the membership functions $\left(\mu_{3}(x)\right.$ and $\left.\mu_{4}(x)\right)$ of two objective functions are linear between $\left(d_{p}^{M}\right)^{*}$ and $\left(d_{p}^{M}\right)^{-}$, they take the following form:

$$
\begin{aligned}
& \left(d_{p}^{P I S^{M}}\right)^{*}=\min _{x \in \mathrm{G}} d_{p}^{P I S^{M}}(\boldsymbol{x}) \text { and the solution is } \boldsymbol{x}^{P I S}, \\
& \left(d_{p}^{N I S^{M}}\right)^{*}=\max _{x \in \mathrm{G}} d_{p}^{N I S^{M}}(\boldsymbol{x}) \text { and the solution is } \boldsymbol{x}^{N I S}, \\
& \left(d_{p}^{P I S^{M}}\right)^{-}=d_{p}^{P I S^{M}}\left(\boldsymbol{x}^{N I S}\right) \text { or }\left(d_{p}^{P I S^{M}}\right)^{-}=\max _{x \in \mathrm{G}} d_{p}^{P I S^{M}}(\boldsymbol{x}) \text { and } \\
& \left(d_{p}^{N I S^{M}}\right)^{-}=d_{p}^{N I S^{M}}\left(\boldsymbol{x}^{P I S}\right) \text { or }\left(d_{p}^{N I S^{M}}\right)^{*}=\min _{x \in \mathrm{G}} d_{p}^{N I S^{M}}(\boldsymbol{x}) .
\end{aligned}
$$

And also, assume that $\mathrm{d}_{p}^{M^{*}}=\left(\left(d_{p}^{P I S^{M}}\right)^{*},\left(d_{p}^{N I S^{M}}\right)^{*}\right)$ and $\mathrm{d}_{p}^{M^{-}}=\left(\left(d_{p}^{P I S^{M}}\right)^{-},\left(d_{p}^{N I S^{M}}\right)^{-}\right)$. Then, based on the preference concept, we assign a larger degree to the one with shorter distance from the PIS for $\mu_{3}(x) \equiv \mu_{d_{p}^{P S^{M}}}(\boldsymbol{x})$ and assign a larger degree to the one with farther distance from NIS for $\mu_{4}(\boldsymbol{x}) \equiv \mu_{d_{p}^{N I S} M}(\boldsymbol{x})$. Therefore, as shown in Figure $1, \mu_{3}(\boldsymbol{x})$ and $\mu_{4}(\boldsymbol{x})$ can be obtained as follows (Lia et. al., 1994; Abo-Sinna and Amer, 2000; Abo-Sinna, 2001; Abo-Sinna et al., 2008):

$$
\begin{aligned}
& \mu_{3}(\boldsymbol{x})=\left\{\begin{array}{llc}
1 & \text { if } & d_{p}^{P I S^{M}}(\boldsymbol{x})<\left(d_{p}^{P I S^{M}}\right)^{*} \\
1-\frac{d_{p}^{P I S^{M}}(\boldsymbol{x})-\left(d_{p}^{P I S^{M}}\right)^{*}}{\left(d_{p}^{P I S^{M}}\right)^{-}-\left(d_{p}^{P I S^{M}}\right)^{*}} & \text { if } & \left(d_{p}^{P I S^{M}}\right)^{*} \leq d_{p}^{P I S^{M}}(\boldsymbol{x}) \leq\left(d_{p}^{P P S^{M}}\right)^{-} \\
0 & \text { if } \quad\left(d_{p}^{P I S^{M}}\right)^{-}<d_{p}^{P I S^{M}}(\boldsymbol{x})
\end{array}\right. \\
& \mu_{4}(\boldsymbol{x})=\left\{\begin{array}{llc}
1 & \text { if } & d_{p}^{N I S^{M}}(\boldsymbol{x}) \leq\left(d_{p}^{N I S^{M}}\right)^{*} \\
1-\frac{\left(d_{p}^{N I S^{M}}\right)^{*}-d_{p}^{N I S^{M}}(\boldsymbol{x})}{\left(d_{p}^{N I S^{M}}\right)^{*}-\left(d_{p}^{N I S^{M}}\right)^{-}} & \text {if } & \left(d_{p}^{N I S^{M}}\right)^{-} \leq d_{p}^{N S^{B}}(\boldsymbol{x}) \leq\left(d_{p}^{N I S^{M}}\right)^{*} \\
0 & \text { if } & d_{p}^{N I S^{M}}(\boldsymbol{x})<\left(d_{p}^{N I S^{M}}\right)^{-}
\end{array}\right.
\end{aligned}
$$

By applying the max-min decision model, which is proposed by Bellman and Zadeh (1970) and extended by Zimmermann (1978) and Zimmermann (1987), we can resolve (20) and obtaining the maximizing solution of model (20), $\boldsymbol{x}^{*}=\left(x_{1}^{*}, x_{2}^{*}, \ldots, x_{q}^{*}\right)$, by solving the following problem: 
Military Technical College

Kobry Elkobbah,

Cairo, Egypt

May $29-31,2012$

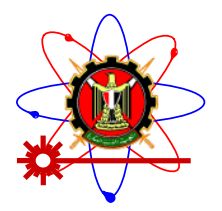

$6^{\text {th }}$ International Conference

on Mathematics and

Engineering Physics

(ICMEP-6)

$$
\mu_{D}(\boldsymbol{x})=\max _{\boldsymbol{x} \in G}\left\{\min \left(\mu_{3}(\boldsymbol{x}), \mu_{4}(\boldsymbol{x})\right)\right\}
$$

where $x_{j}^{*}=\left(x_{j 1}^{*}, x_{j 2}^{*}, \ldots, x_{j n_{j}}^{*}\right), j=1,2, \ldots, q$.

If $\delta=\min \left(\mu_{3}(\boldsymbol{x}), \mu_{4}(\boldsymbol{x})\right)$, the model (20) is equivalent to the form of Tchebycheff model (Bellman and Zadeh, 1970; Zimmermann, 1987; Lai and Hwang, 1992; Lia et. al., 1994; AboSinna and Amer, 2000; Abo-Sinna, 2001; Abo-Sinna et al., 2008), which is equivalent to the following model:

$$
\begin{aligned}
& \max \delta \\
& \text { subject to } \\
& \mu_{3}(\boldsymbol{x}) \geq \delta \quad, \quad \mu_{4}(\boldsymbol{x}) \geq 4, \quad \delta \in[0,1] \text { and } \\
& \boldsymbol{x} \in \boldsymbol{G}=\left\{\boldsymbol{x} \in \mathrm{R}^{\mathrm{n}} \mid g_{i}(\boldsymbol{x}) \leq 0, i=1,2, \ldots, s\right\} \neq \boldsymbol{\phi}
\end{aligned}
$$

where $\delta$ is the satisfactory level for both criteria of the shortest distance from the PIS and the farthest distance from the NIS. It is well known that if the optimal solution of (28) is the vector $\left(\delta, x^{*}\right)$, then $\boldsymbol{x}^{*}$ is the maximizing solution of model (20).

Finally, as discussed in section (4-1), in order to generate the satisfactory solution of the MLN-MODM problem, $\boldsymbol{x}^{*}$, the final proposed model that includes the membership functions (17) for the upper levels decision variables vectors controlled by $q-1$ upper levels, $x_{k}^{k^{*}}=\left(x_{k 1}^{k^{*}}, x_{k 2}^{k^{*}}, \ldots, x_{k n_{k}}^{k^{*}}\right), k=1,2, \ldots, q-1$, is presented in this paper as:

$\max \delta$

subject to

$$
\begin{aligned}
& 1-\frac{d_{p}^{P I S^{M}}(\boldsymbol{x})-\left(d_{p}^{P I S^{M}}\right)^{*}}{\left(d_{p}^{P I S^{M}}\right)^{-}-\left(d_{p}^{P I S^{M}}\right)^{*}} \geq \delta, 1-\frac{\left(d_{p}^{N I S^{M}}\right)^{*}-d_{p}^{N I S^{M}}(\boldsymbol{x})}{\left(d_{p}^{N I S^{M}}\right)^{*}-\left(d_{p}^{N I S^{M}}\right)^{-}} \geq \delta, \\
& \frac{x_{k j}^{k}-\left(x_{k j}^{k^{*}}-t_{j}^{k}{ }^{L}\right)}{t_{j}^{k_{L}}} \geq \delta, k=1,2, \ldots, q-1, j=1,2, \ldots, n_{k}, \\
& \frac{\left(x_{k j}^{k^{*}}+t_{j}^{k_{R}}\right)-x_{k j}^{k}}{t_{j}^{k_{R}}} \geq \delta, k=1,2, \ldots, q-1, j=1,2, \ldots, n_{k}, \\
& \boldsymbol{x} \in \boldsymbol{G}=\left\{\boldsymbol{x} \in \mathrm{R}^{\mathrm{n}} \mid g_{i}(\boldsymbol{x}) \leq 0, i=1,2, \ldots, s\right\} \neq \phi \text { and } \\
& \delta \in[0,1] .
\end{aligned}
$$


Military Technical College

Kobry Elkobbah,

Cairo, Egypt

May 29-31,2012 $6^{\text {th }}$ International Conference

on Mathematics and

Engineering Physics

(ICMEP-6)

\section{The TOPSIS Algorithms for MLN-MODM Problems}

The TOPSIS model (29) provides a satisfactory decision for all decision-makers of the MLN-MODM problem. Following the above discussion, this paper presents two interactive TOPSIS algorithms to the proposed TOPSIS approach for solving MLN-MODM problems.

\subsection{The First TOPSIS Algorithm to MLN-MOLP problems}

The first interactive TOPSIS algorithm, proposed in this paper, includes all satisfactory decisions for all $q$-1 upper levels MODM problems, with possible tolerances, which are described by membership functions of fuzzy set theory. These satisfactory decisions are evaluated separately by solving the corresponding single-level MODM problems. Following the above discussion, the first proposed interactive TOPSIS algorithm for solving MLN-MODM problems is given as follows:

\section{TOPSIS Alg I:}

Step 1. Calculate the individual minimum and maximum values of all the objective functions in all levels under the given constraints.

Step 2. Set $k=1$

Step 3. Solve the $k^{\text {th }}$-level MODM problem using Alg A, $\mathbf{l}=k$, and return with $x_{k}^{k^{*}}=\left(x_{k 1}^{k^{*}}, x_{k 2}^{k^{*}}, \ldots, x_{k n_{k}}^{k^{*}}\right), t_{j}^{k_{L}}$ and $t_{j}^{k_{R}}, j=1,2, \ldots, n_{k}$.

Step 4. $k=k+1$.

Step 5. If $k>q-1$, then go to Step 6 ; otherwise go to Step 3.

Step 6. Construct the PIS payoff table of the MLN-MODM problem and obtain $F^{*}=\left(f_{11}^{*}, \ldots, f_{1 m_{1}}^{*}, f_{21}^{*}, \ldots, f_{2 m_{2}}^{*}, \ldots, f_{q 1}^{*}, \ldots, f_{q m_{q}}^{*}\right)$, the individual positive ideal solutions for all levels.

Step 7. Construct the NIS payoff table of the MLN-MODM problem and obtain $F^{-}=\left(f_{11}^{-}, \ldots, f_{1 m_{1}}^{-}, f_{21}^{-}, \ldots, f_{2 m_{2}}^{-}, f_{q 1}^{-}, \ldots, f_{q m_{q}}^{-}\right)$, the individual negative ideal solutions for all levels.

Step 8. Use Eq. (18) and Eq. (19) to construct $d_{p}^{P I S^{M}}(\boldsymbol{x})$ and $d_{p}^{N I S^{M}}(\boldsymbol{x})$, respectively.

Step 9. Construct the payoff table of problem (20) and obtain $\mathrm{d}_{p}^{M^{*}}$ and $\mathrm{d}_{p}^{M^{-}}$.

Step 10. Elicit the membership functions $\mu_{d_{p}^{P I S^{M}}}(\boldsymbol{x})$ and $\mu_{d_{p}^{N I S^{M}}}(\boldsymbol{x})$, Eq. (25) and Eq. (26).

Step 11. Elicit the membership functions $\mu_{x_{k j}^{k}}\left(x_{k j}^{k}\right), k=1,2, \ldots, q-1, j=1,2, \ldots, n_{k}$ in Eq.(17) for the decision vectors $x_{k}^{k^{*}}=\left(x_{k 1}^{k^{*}}, x_{k 2}^{k^{*}}, \ldots, x_{k n_{k}}^{k^{*}}\right), k=1,2, \ldots, q-1, j=1,2, \ldots, n_{k}$.

Step 12. Formulate the Model (29) for the MLN-MODM problem.

Step 13. Solve Model (29) to get $\boldsymbol{x}^{*}$. 
Military Technical College

Kobry Elkobbah,

Cairo, Egypt

May 29-31,2012

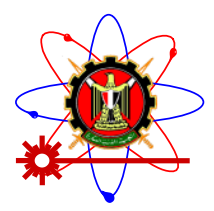

$6^{\text {th }}$ International Conference

on Mathematics and

Engineering Physics

(ICMEP-6)

Step 14. If the DMs are satisfied with the candidate solution in Step 13, then go to Step 15, else go to Step 16.

Step 15. Stop with a satisfactory solution, $\boldsymbol{x}^{*}$, to the MLN-MODM problem.

Step 16. Modify the maximum negative and positive tolerances values on the decision vectors $x_{k}^{k^{*}}=\left(x_{k 1}^{k_{1}^{*}}, x_{k 2}^{k_{2}^{*}}, \ldots, x_{k n_{k}}^{k^{*}}\right), t_{j}^{k_{L}}$ and $t_{j}^{k_{R}}, k=1,2, \ldots, q-1, j=1,2, \ldots, n_{k}$, go to

Step 11.

\subsection{The Second TOPSIS Algorithm to TLN-MOLP problems}

In Alg I, the final model (29) contains the membership functions of the decision variables controlled by $q-1$ upper levels, which separately solved for the $1^{\text {th }}$-level MOLP problem, $1=1,2, \ldots, p-1$. The second proposed algorithm lexicographically (level by level) solves $p$ MODM problems that take into consideration the satisfactory decisions of the upper levels (Baky, 2010). The solution procedure starts with the MODM problem of $\mathrm{DM}_{1}$ obtaining the satisfactory solution. A relaxation of the $\mathrm{DM}_{1}$ decisions is considered to avoid decision deadlock. These decisions of $\mathrm{DM}_{1}$ are modeled by membership functions of fuzzy set theory and passed to the $\mathrm{DM}_{2}$ as additional constrains. Then, the distance function from the positive ideal solution, $d_{p}^{P I S}$, and the distance function from the negative ideal solution, $d_{p}^{N I S}$, are modelled to include both the objective functions of the first and the second levels. . Thereafter, the attained solution is sent to the $\mathrm{DM}_{3}$ who seeks the solution in a similar manner. The process is repeated until the last level of the MLN-MODM problem is reached. In other words, the distance function formulation of $d_{p}^{P I S}$ and $d_{p}^{N I S}$ while solving the $1^{\text {th }}$-level MODM problem, $1=2,3, \ldots, q$, take the following form:

$$
\begin{aligned}
& d_{p}^{P I S^{M}}(\boldsymbol{x})=\left\{\sum_{i=1}^{1}\left(\sum_{j=1}^{m_{i}} \lambda_{i j}^{p}\left[\frac{f_{i j}^{*}-f_{i j}(\boldsymbol{x})}{f_{i j}^{*}-f_{i j}^{-}}\right]^{p}\right)\right\}^{1 / p} \\
& d_{p}^{N I S^{M}}(\boldsymbol{x})=\left\{\sum_{i=1}^{1}\left(\sum_{j=1}^{m_{i}} \lambda_{i j}^{p}\left[\frac{f_{i j}(\boldsymbol{x})-f_{i j}^{-}}{f_{i j}^{*}-f_{i j}^{-}}\right]^{p}\right)\right\}^{1 / p}
\end{aligned}
$$

And the model formulation (29) for $1^{\text {th }}$-level MODM problem, $1=2,3, \ldots, q$, is modified to get the satisfactory solution of the upper $1^{\text {th }}$-levels MODM problems as:

$\max \delta$

subject to

$$
1-\frac{d_{p}^{P I S^{M}}(\boldsymbol{x})-\left(d_{p}^{P I S^{M}}\right)^{*}}{\left(d_{p}^{P I S^{M}}\right)^{-}-\left(d_{p}^{P I S^{M}}\right)^{*}} \geq \delta, 1-\frac{\left(d_{p}^{N I S^{M}}\right)^{*}-d_{p}^{N I S^{M}}(\boldsymbol{x})}{\left(d_{p}^{N I S^{M}}\right)^{*}-\left(d_{p}^{N I S^{M}}\right)^{-}} \geq \delta,
$$


Military Technical College

Kobry Elkobbah,

Cairo, Egypt

May $29-31,2012$ $6^{\text {th }}$ International Conference

on Mathematics and

Engineering Physics

(ICMEP-6)

$$
\begin{aligned}
& \frac{x_{k j}^{k}-\left(x_{k j}^{k^{*}}-t_{j}^{k_{L}}\right)}{t_{j}^{k_{L}}} \geq \delta, k=1,2, \ldots, 1-1, j=1,2, \ldots, n_{k}, \\
& \frac{\left(x_{k j}^{k^{*}}+t_{j}^{k_{R}}\right)-x_{k j}^{k}}{t_{j}^{k_{R}}} \geq \delta, k=1,2, \ldots, 1-1, j=1,2, \ldots, n_{k}, \\
& \boldsymbol{x} \in \boldsymbol{G}=\left\{\boldsymbol{x} \in \mathrm{R}^{\mathrm{n}} \mid g_{i}(\boldsymbol{x}) \leq 0, i=1,2, \ldots, s\right\} \neq \phi \text { and } \\
& \delta \in[0,1] .
\end{aligned}
$$

Following this discussion, we are now in a position to introduce the second proposed interactive TOPSIS algorithm for solving ML-MOLP problems:

\section{TOPSIS Alg II:}

Step 1. Calculate the individual minimum and maximum values of all the objective functions in all levels under the given constraints.

Step 2. Set $1=1$

Step 3. Solve the $1^{\text {th }}$-level MODM using Alg A and return with $x_{1}^{1^{*}}=\left(x_{11}^{1^{*}}, x_{12}^{1^{*}}, \ldots, x_{1 n_{1}}^{1^{*}}\right)$, $t_{j}^{1}{ }^{L}$ and $t_{j}^{1}{ }^{R}, j=1,2, \ldots, n_{1}$.

Step 4. $1=1+1$.

Step 5. Construct the PIS payoff table until the $1^{\text {th }}$-level MODM problem and obtain $F^{*}=\left(f_{11}^{*}, \ldots, f_{1 m_{1}}^{*}, f_{21}^{*}, \ldots, f_{2 m_{2}}^{*}, \ldots, f_{11}^{*}, \ldots, f_{1 m_{1}}^{*}\right)$, the individual positive ideal solutions for 1 levels .

Step 6. Construct the NIS payoff table of the until the $1^{\text {th }}$-level MODM problem and obtain $F^{-}=\left(f_{11}^{-}, \ldots, f_{1 m_{1}}^{-}, f_{21}^{-}, \ldots, f_{2 m_{2}}^{-}, \ldots, f_{11}^{-}, \ldots, f_{1 m_{1}}^{-}\right)$, the individual negative ideal solutions for 1 levels.

Step 7. Use Eq. (30) and Eq. (31) to construct $d_{p}^{P I S^{M}}(\boldsymbol{x})$ and $d_{p}^{N I S^{M}}(\boldsymbol{x})$, respectively.

Step 8. Construct the payoff table of problem (20) and obtain $\mathrm{d}_{p}^{M^{*}}$ and $\mathrm{d}_{p}^{M^{-}}$.

Step 9. Elicit the membership functions $\mu_{d_{p}^{P I S^{M}}}(\boldsymbol{x})$ and $\mu_{d_{p}^{N I S^{M}}}(\boldsymbol{x})$, Eq. (25) and Eq. (26).

Step 10. Elicit the membership functions $\mu_{x_{k j}^{k}}\left(x_{k j}^{k}\right), k=1,2, \ldots, 1-1, j=1,2, \ldots, n_{k}$ in Eq.(17) for the decision vectors $x_{k}^{k^{*}}=\left(x_{k 1}^{k^{*}}, x_{k 2}^{k^{*}}, \ldots, x_{k n_{k}}^{k^{*}}\right), k=1,2, \ldots, 1-1, j=1,2, \ldots, n_{k}$.

Step 11. Formulate the Model (31) for the upper $1^{\text {th }}$-levels MODM problems.

Step 12. Solve Model (31) to get $\boldsymbol{x}^{1^{*}}=\left(x_{1}^{1^{*}}, x_{2}^{1^{*}}, \ldots, x_{q}^{1^{*}}\right), x_{1}^{1^{*}}=\left(x_{11}^{1^{*}}, x_{12}^{1^{*}}, \ldots, x_{1 n_{1}}^{1^{*}}\right)$.

Step 13. If the upper DMs are satisfied with the candidate solution in Step 12, then go to Step 14, else go to Step 15.

Step 14. If $1=q$, then stop with a satisfactory solution, $\boldsymbol{x}^{*} \equiv \boldsymbol{x}^{1^{*}}=\left(x_{1}^{1^{*}}, x_{2}^{1^{*}}, \ldots, x_{q}^{1^{*}}\right)$, to the 
Military Technical College

Kobry Elkobbah,

Cairo, Egypt

May $29-31,2012$ $6^{\text {th }}$ International Conference

on Mathematics and

Engineering Physics

(ICMEP-6)

MLN-MODM problem; otherwise go to Step 4.

Step 15. Modify the maximum negative and positive tolerances values on the decision vectors $x_{k}^{k^{*}}=\left(x_{k 1}^{k^{*}}, x_{k 2}^{k^{*}}, \ldots, x_{k n_{k}}^{k^{*}}\right), t_{j}^{k_{L}}$ and $t_{j}^{k_{R}}, k=1,2, \ldots, 1-1, j=1,2, \ldots, n_{k}$. Go to

Step 10.

\section{Illustrative Numerical example}

The following numerical example studied by Osman et al. (2003) is considered to illustrate the proposed TOPSIS approach and proposed TOPSIS algorithms for solving MLN-MODM problems:

[1 $1^{\text {st }}$ Level $] \quad \operatorname{Max}_{x_{1}}\left(f_{11}=x_{1}+x_{2}+x_{3}, f_{12}=x_{1}^{2}+x_{2}^{2}+x_{3}^{2}\right)$

where $x_{2}$ and $x_{3}$ solve

$\left[2^{\text {nd }}\right.$ Level $] \quad \operatorname{Max}_{x_{2}}\left(f_{21}=x_{1}^{2}+x_{2}+x_{3}, f_{22}=\left(x_{1}-1\right)^{2}+x_{2}^{2}+x_{3}^{2}\right)$

where $x_{3}$ solves

$\left[3^{\text {rd }}\right.$ Level $] \quad \operatorname{Max}_{x_{3}}\left(f_{31}=x_{1}^{2}+x_{2}^{2}+x_{3}, f_{32}=\left(x_{1}-1\right)^{2}+\left(x_{2}+1\right)^{2}+\left(x_{3}-1\right)^{2}\right)$

subject to

$$
\boldsymbol{x}=\left(x_{1}, x_{2}, x_{3}\right) \in \mathrm{G}=\left\{\boldsymbol{x} \mid x_{1}+2 x_{2}+x_{3} \leq 8,2 x_{1}+x_{2}+x_{3} \leq 7, x_{1}+x_{2}+x_{3} \leq 5, x_{1}, x_{2}, x_{3} \geq 0\right\}
$$

Table 1 summarizes minimum and maximum individual optimal solutions, of all objectives functions for the two levels of the BL-MODM problem, subjected to given constraints, $G$.

\section{Table 1}

minimum and maximum individual optimal solutions

\begin{tabular}{|c|c|c|c|c|c|c|}
\cline { 2 - 7 } \multicolumn{1}{c|}{} & $f_{11}$ & $f_{12}$ & $f_{21}$ & $f_{22}$ & $f_{31}$ & $f_{32}$ \\
\hline $\min _{G} f_{\mathrm{ij}}$ & 0 & 0 & 0 & 0 & 0 & 1 \\
\hline $\max _{G} f_{\mathrm{ij}}$ & 5 & 25 & 12.25 & 26 & 16 & 27 \\
\hline
\end{tabular}

The first Algorithm, Alg I, can be explained through the solution procedure of the second algorithm, Alg II. Then, following Alg II, the proposed TOPSIS approach to MLN-MODM problems proceeds as:

\section{The satisfactory solution of first-level MODM problem:}

Firstly, Table 2 and Table 3 show the PIS and NIS payoff tables for the first-level MODM problem:

$$
\begin{aligned}
& \underset{x_{1}}{\operatorname{Max}}\left(f_{11}=x_{1}+x_{2}+x_{3}, f_{12}=x_{1}^{2}+x_{2}^{2}+x_{3}^{2}\right) \\
& \text { subject to } \boldsymbol{x}=\left(x_{1}, x_{2}, x_{3}\right) \in \mathrm{G}
\end{aligned}
$$

Table 2

PIS payoff table of problem (33) and (34) 
Military Technical College

Kobry Elkobbah,

Cairo, Egypt

May $29-31,2012$ $6^{\text {th }}$ International Conference

on Mathematics and

Engineering Physics

(ICMEP-6)

\begin{tabular}{|c|c|c|c|c|c|}
\cline { 2 - 6 } \multicolumn{1}{c|}{} & $f_{11}$ & $f_{21}$ & $x_{1}$ & $x_{2}$ & $x_{3}$ \\
\hline $\max _{G} f_{11}$ & $5^{*}$ & 25 & 0 & 0 & 5 \\
\hline $\max _{G} f_{12}$ & 5 & $25^{*}$ & 0 & 0 & 5 \\
\hline
\end{tabular}

$F^{1^{*}}=\left(f_{11}^{*}, f_{12}^{*}\right)=(5,25)$

Table 3

NIS payoff table of problem (33) and (34)

\begin{tabular}{|c|c|c|c|c|c|}
\cline { 2 - 6 } \multicolumn{1}{c|}{} & $f_{11}$ & $f_{21}$ & $x_{1}$ & $x_{2}$ & $x_{3}$ \\
\hline $\min _{G} f_{11}$ & $0^{-}$ & 0 & 0 & 0 & 0 \\
\hline $\min _{G} f_{12}$ & 0 & -0 & 0 & 0 & 0 \\
\hline
\end{tabular}

$F^{1^{-}}=\left(f_{11}^{-}, f_{12}^{-}\right)=(0,0)$

Assume that $\lambda_{1}=\lambda_{2}=0.5$, the equations for $d_{p}^{P I S^{1}}(\boldsymbol{x})$ and $d_{p}^{N I S^{1}}(\boldsymbol{x})$ when $p=2$ are:

$$
\begin{aligned}
& F_{1}^{1}=d_{2}^{P I S^{1}}(\boldsymbol{x})=\sqrt{0.5^{2}\left[\frac{5-x_{1}-x_{2}-x_{3}}{5-0}\right]^{2}+0.5^{2}\left[\frac{25-x_{1}^{2}-x_{2}^{2}-x_{3}^{2}}{25-0}\right]^{2}} \\
& F_{1}^{1}=d_{2}^{P I S^{1}}(\boldsymbol{x})=\sqrt{0.01\left[5-x_{1}-x_{2}-x_{3}\right]^{2}+0.0004\left[25-x_{1}^{2}-x_{2}^{2}-x_{3}^{2}\right]^{2}}, \\
& F_{2}^{1}=d_{2}^{N I S^{1}}(\boldsymbol{x})=\sqrt{0.01\left[x_{1}+x_{2}+x_{3}\right]^{2}+0.0004\left[x_{1}^{2}+x_{2}^{2}+x_{3}^{2}\right]^{2}} .
\end{aligned}
$$

Next, To formulate model (16) the payoff table of (8) is shown in Table 4:

Table 4

The payoff table of (8) when $p=2$

\begin{tabular}{|c|c|c|c|c|c|}
\cline { 2 - 6 } \multicolumn{1}{c|}{} & $F_{1}^{1}$ & $F_{2}^{1}$ & $x_{1}$ & $x_{2}$ & $x_{3}$ \\
\hline Min $F_{1}^{1}$ & $0^{*}$ & $0.707^{-}$ & 0 & 0 & 5 \\
\hline $\operatorname{Max} F_{2}^{1}$ & $0^{-}$ & $0.707^{*}$ & 0 & 0 & 5 \\
\hline
\end{tabular}

Also, Max $F_{1}^{1}=0.707$ at $(0,0,0)$ and $\operatorname{Min} F_{2}^{1}=0$ at $(0,0,5)$. Thus, we have $\mathrm{d}_{2}^{1 *}=(0,0.707)$ and $\mathrm{d}_{2}^{1^{-}}=(0.707,0)$ (as proposed in this paper). Therefore, the membership functions $\mu_{1}(\boldsymbol{x})$ and $\mu_{2}(\boldsymbol{x})$ can be obtained as:

$$
\begin{aligned}
& \mu_{F_{1}^{1}}(x)=1-\frac{F_{1}^{1}-0}{0.707-0}=1-1.414 F_{1}^{1} \\
& \mu_{F_{2}^{1}}(x)=1-\frac{0.707-F_{2}^{1}}{0.707-0}=F_{2}^{1}
\end{aligned}
$$


Military Technical College

Kobry Elkobbah,

Cairo, Egypt

May $29-31,2012$ $6^{\text {th }}$ International Conference

on Mathematics and

Engineering Physics

(ICMEP-6)

And then, the equivalent TOPSIS formulation for the first-level MODM problem is obtained as:

$\max \alpha$

subject to

$$
\begin{aligned}
& 1-1.414 F_{1}^{1} \geq \alpha, \\
& F_{2}^{1} \geq \alpha, \\
& \alpha \in[0,1], \text { and } \boldsymbol{x}=\left(x_{1}, x_{2}, x_{3}\right) \in \mathrm{G}
\end{aligned}
$$

The maximum satisfactory level $\alpha=0.9985 \cong 1$ is achieved for the solution $\boldsymbol{x}^{\mathbf{1}^{*}}=\left(x_{1}^{1^{*}}, x_{2}^{1^{*}}, x_{3}^{1^{*}}\right)=(0,0,5)$ and $\left(f_{11}, f_{12}\right)=(5,25)$. Let the upper level DM decide $x_{1}^{1^{*}}=0$ with positive tolerance $t_{1}^{R}=1$ (one sided membership function (Sinha, 2003; Pramanik and Roy, 2006).

\section{The satisfactory solution of the first-level and second-level MODM problems:}

Table 5 and Table 6 show the PIS and NIS payoff tables for the second-level MODM problem:

$$
\begin{aligned}
& \operatorname{Max}_{x_{2}}\left(f_{21}=x_{1}^{2}+x_{2}+x_{3}, f_{22}=\left(x_{1}-1\right)^{2}+x_{2}^{2}+x_{3}^{2}\right) \\
& \text { subject to } \boldsymbol{x}=\left(x_{1}, x_{2}, x_{3}\right) \in \mathrm{G}
\end{aligned}
$$

Assume that $\lambda_{i}=0.25, i=1,2,3,4$, the equations for $d_{p}^{P I S^{2}}(\boldsymbol{x})$ and $d_{p}^{N I S^{2}}(\boldsymbol{x})$ when $p=2$ are:

$$
\begin{aligned}
& P_{1}^{2}=d_{2}^{P I S^{2}}(\boldsymbol{x})=\left\{\begin{array}{l}
0.25^{2}\left[\frac{5-x_{1}-x_{2}-x_{3}}{5-0}\right]^{2}+0.25^{2}\left[\frac{25-x_{1}^{2}-x_{2}^{2}-x_{3}^{2}}{25-0}\right]^{2}+ \\
0.25^{2}\left[\frac{12.25-x_{1}^{2}-x_{2}-x_{3}}{12.25-0}\right]^{2}+0.25^{2}\left[\frac{26-\left(x_{1}-1\right)^{2}-x_{2}^{2}-x_{3}^{2}}{26-0}\right]^{2}
\end{array}\right\}^{1 / 2} \\
& P_{1}^{2}=d_{2}^{P I S^{2}}(\boldsymbol{x})=\left\{\begin{array}{l}
0.0025\left[5-x_{1}-x_{2}-x_{3}\right]^{2}+0.0001\left[25-x_{1}^{2}-x_{2}^{2}-x_{3}^{2}\right]^{2}+ \\
0.00042\left[12.25-x_{1}^{2}-x_{2}-x_{3}\right]^{2}+0.000093\left[26-\left(x_{1}-1\right)^{2}-x_{2}^{2}-x_{3}^{2}\right]^{2}
\end{array}\right\} \\
& P_{2}^{2}=d_{2}^{N I S^{2}}(\boldsymbol{x})=\left\{\begin{array}{l}
0.0025\left[x_{1}+x_{2}+x_{3}\right]^{2}+0.0001\left[x_{1}^{2}+x_{2}^{2}+x_{3}^{2}\right]^{2}+ \\
0.00042\left[x_{1}^{2}+x_{2}+x_{3}\right]^{2}+0.000093\left[\left(x_{1}-1\right)^{2}+x_{2}^{2}+x_{3}^{2}\right]^{2}
\end{array}\right\}^{1 / 2}
\end{aligned}
$$

Table 5

PIS payoff table of problem (35) and (36)

\begin{tabular}{|c|c|c|c|c|c|}
\cline { 2 - 6 } \multicolumn{1}{c|}{} & $f_{21}$ & $f_{22}$ & $x_{1}$ & $x_{2}$ & $x_{3}$ \\
\hline $\max _{G} f_{21}$ & $12.25^{*}$ & 6.25 & 3.5 & 0 & 0 \\
\hline
\end{tabular}


Military Technical College

Kobry Elkobbah,

Cairo, Egypt

May $29-31,2012$ $6^{\text {th }}$ International Conference

on Mathematics and

Engineering Physics

(ICMEP-6)

\begin{tabular}{|c|c|c|c|c|c|}
\hline $\max _{G} f_{22}$ & 5 & $26^{*}$ & 0 & 0 & 5 \\
\hline
\end{tabular}
$F^{L^{*}}=\left(f_{21}^{*}, f_{22}^{*}\right)=(12.25,26)$

Table 6

NIS payoff table of problem (35) and (36)

\begin{tabular}{|l|l|l|l|l|l|}
\cline { 2 - 6 } \multicolumn{1}{c|}{} & $f_{21}$ & $f_{22}$ & $x_{1}$ & $x_{2}$ & $x_{3}$ \\
\hline $\min _{G} f_{21}$ & 0 & 1 & 0 & 0 & 0 \\
\hline $\min _{G} f_{22}$ & 1 & 0 & 1 & 0 & 0 \\
\hline
\end{tabular}

Next, To formulate model (29) the payoff table of (20) is shown in Table 7:

Table 7

The payoff table of (20), when

\begin{tabular}{|c|c|c|c|c|c|}
\cline { 2 - 6 } \multicolumn{1}{c|}{} & $P_{1}^{2}$ & $P_{2}^{2}$ & $x_{1}$ & $x_{2}$ & $x_{3}$ \\
\hline Min $P_{1}^{2}$ & $0.1486^{*}$ & $0.445^{-}$ & 0 & 0 & 5 \\
\hline Max $P_{2}^{2}$ & $0.1486^{-}$ & $0.445^{*}$ & 0 & 0 & 5 \\
\hline
\end{tabular}

Also, Max $P_{1}^{2}=0.496$ at $(0,0,0)$ and $\operatorname{Min} P_{2}^{2}=0.009$ at $(0,0,0.0614)$. Thus, we have $\mathrm{d}_{2}^{2 *}=(0.1486,0.445)$ and $\mathrm{d}_{p}^{2}=(0.496,0.009) \quad$ (as proposed in this paper). Similar to the TOPSIS formulation of the first-level MODM problem, the equivalent TOPSIS formulation for the first-level and second-level MODM problems is obtained as:

$\max \beta$

subject to

$$
\begin{aligned}
& -2.89 P_{1}^{2}+1.43 \geq \beta \\
& 2.294 P_{2}^{B}-0.021 \geq \beta \\
& 1-x_{1} \geq \beta \\
& \beta \in[0,1], \text { and } x=\left(x_{1}, x_{2}, x_{3}\right) \in \mathrm{G}
\end{aligned}
$$

The maximum overall satisfactory level $\beta=1$ is achieved for the solution $\boldsymbol{x}^{2^{*}}=\left(x_{1}^{2^{*}}, x_{2}^{2^{*}}, x_{3}^{2^{*}}\right)=(0,0.00282,4.997)$. Let the second-level DM decide $x_{2}^{2^{*}}=0.00282$ with positive tolerance $t_{2}^{R}=0.5$ and negative tolerance $t_{2}^{L}=0.00282$.

\section{The TL-MODM problem:}


Military Technical College

Kobry Elkobbah,

Cairo, Egypt

May 29-31,2012

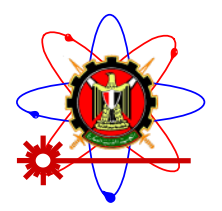

$6^{\text {th }}$ International Conference

on Mathematics and

Engineering Physics

(ICMEP-6)

Similarly, in the same way, the equivalent TOPSIS formulation for the TL-MODM problem is:

$\max \delta$

subject to

$$
\begin{aligned}
& -3.876 G_{1}^{3}+1.548 \geq \delta \\
& 3.296 G_{2}^{3}-0.042 \geq \delta \\
& 1-x_{1} \geq \delta \\
& \frac{x_{2}-(0.00282-0.00282)}{0.00282} \geq \delta \\
& \frac{(0.00282+0.5)-x_{2}}{0.00282} \geq \delta \\
& \delta \in[0,1], \text { and } x=\left(x_{1}, x_{2}, x_{3}\right) \in \mathrm{G}
\end{aligned}
$$

where: $\lambda_{i}=\frac{1}{6}, i=1,2, \ldots, 6$ and

$$
\begin{aligned}
G_{1}^{3}=d_{2}^{P I S^{3}}(\boldsymbol{x})=\left\{\begin{array}{l}
\left(\frac{1}{6}\right)^{2}\left[\frac{5-x_{1}-x_{2}-x_{3}}{5-0}\right]^{2}+\left(\frac{1}{6}\right)^{2}\left[\frac{25-x_{1}^{2}-x_{2}^{2}-x_{3}^{2}}{25-0}\right]^{2}+ \\
\left(\frac{1}{6}\right)^{2}\left[\frac{12.25-x_{1}^{2}-x_{2}-x_{3}}{12.25-0}\right]^{2}+\left(\frac{1}{6}\right)^{2}\left[\frac{26-\left(x_{1}-1\right)^{2}-x_{2}^{2}-x_{3}^{2}}{26-0}\right]^{2}+ \\
\left(\frac{1}{6}\right)^{2}\left[\frac{16-x_{1}^{2}-x_{2}^{2}-x_{3}}{16-0}\right]^{2}+\left(\frac{1}{6}\right)^{2}\left[\frac{27-\left(x_{1}-1\right)^{2}-\left(x_{2}+1\right)^{2}-\left(x_{3}-1\right)^{2}}{27-1}\right]^{2}
\end{array}\right]^{1 / 2} \\
G_{1}^{3}=d_{2}^{P I S^{3}}(\boldsymbol{x})=\left\{\begin{array}{l}
0.00111\left[5-x_{1}-x_{2}-x_{3}\right]^{2}+0.000044\left[25-x_{1}^{2}-x_{2}^{2}-x_{3}^{2}\right]^{2}+ \\
0.000178\left[12.25-x_{1}^{2}-x_{2}-x_{3}\right]^{2}+0.00004\left[26-\left(x_{1}-1\right)^{2}-x_{2}^{2}-x_{3}^{2}\right]^{2}+ \\
0.00012\left[16-x_{1}^{2}-x_{2}^{2}-x_{3}\right]^{2}+0.000038\left[27-\left(x_{1}-1\right)^{2}-\left(x_{2}+1\right)^{2}-\left(x_{3}-1\right)^{2}\right]^{2}
\end{array}\right\} \\
G_{2}^{3}=d_{2}^{N I S^{3}}(\boldsymbol{x})=\left\{\begin{array}{l}
0.00111\left[x_{1}+x_{2}+x_{3}\right]^{2}+0.000044\left[x_{1}^{2}+x_{2}^{2}+x_{3}^{2}\right]^{2}+ \\
0.000178\left[x_{1}^{2}+x_{2}+x_{3}\right]^{2}+0.00004\left[\left(x_{1}-1\right)^{2}+x_{2}^{2}+x_{3}^{2}\right]^{2}+ \\
0.00012\left[x_{1}^{2}+x_{2}^{2}+x_{3}\right]^{2}+0.000038\left[\left(x_{1}-1\right)^{2}+\left(x_{2}+1\right)^{2}+\left(x_{3}-1\right)^{2}-1\right.
\end{array}\right]^{1 / 2}
\end{aligned}
$$

The maximum overall satisfactory level for the TL-MODM problem $\delta=0.91$ is achieved for the solution $\boldsymbol{x}^{*}=\boldsymbol{x}^{3^{*}}=\left(x_{1}^{3^{*}}, x_{2}^{3^{*}}, x_{3}^{3^{*}}\right)=(0,0.0026,4.997)$, with objective function values $f_{11}=4.9996, f_{12}=24.97$, $f_{21}=4.9996, f_{22}=25.97, f_{31}=4.997$ and $f_{32}=17.98$ and with membership function values $\mu_{11}=0.9999, \mu_{12}=0.999, \mu_{21}=0.408, \mu_{22}=0.999, \mu_{31}=0.31$ and $\mu_{32}=0.69$, respectively . 


\section{Military Technical College \\ Kobry Elkobbah, Cairo, Egypt \\ May 29-31,2012}

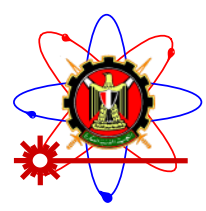

A comparison given in Table 8 between the proposed TOPSIS algorithms, Alg I and Alg II, and that were given in Osman et al. (2003) by Osman et al. clearly shows that the two compromise solutions of Alg I and the interactive algorithm of Osman et al. (2003) are close to one another. Also, it shows that the compromise solution of the proposed TOPSIS Alg II is more preferred than the compromise solution of the interactive algorithm of Osman et al. (2003).

Table 8

Comparison of optimal solutions and satisfactory solutions of the illustrative example based on the proposed TOPSIS algorithms and the interactive algorithm of Osman et al. (2003)

\begin{tabular}{|l|l|l|l|l|l|l|}
\hline $\begin{array}{c}\text { The optimal } \\
\text { solutions }\end{array}$ & \multicolumn{2}{|c|}{$\begin{array}{c}\text { The interactive algorithm of } \\
\text { Osman et al. (2003) }\end{array}$} & \multicolumn{2}{c|}{ The proposed TOPSIS Alg I } & \multicolumn{2}{c|}{ The proposed TOPSIS Alg II } \\
\hline$f_{11}=5$ & $f_{11}=4.99$ & $\mu_{11}=0.998$ & $f_{11}=4.93$ & $\mu_{11}=0.958$ & $f_{11}=4.9996$ & $\mu_{11}=0.9999$ \\
\hline$f_{12}=25$ & $f_{12}=12.45$ & $\mu_{12}=0.498$ & $f_{12}=12.88$ & $\mu_{12}=0.52$ & $f_{12}=24.97$ & $\mu_{12}=0.999$ \\
\hline$f_{21}=12.25$ & $f_{21}=6.7$ & $\mu_{21}=0.547$ & $f_{21}=4.93$ & $\mu_{21}=0.4$ & $f_{21}=4.9996$ & $\mu_{21}=0.408$ \\
\hline$f_{22}=26$ & $f_{22}=9.65$ & $\mu_{22}=0.37$ & $f_{22}=13.88$ & $\mu_{22}=0.534$ & $f_{22}=25.97$ & $\mu_{22}=0.999$ \\
\hline$f_{31}=16$ & $f_{31}=12.55$ & $\mu_{31}=0.78$ & $f_{31}=11.3$ & $\mu_{31}=0.71$ & $f_{31}=4.997$ & $\mu_{31}=0.31$ \\
\hline$f_{32}=27$ & $f_{32}=17.35$ & $\mu_{32}=0.67$ & $f_{32}=18.34$ & $\mu_{32}=0.71$ & $f_{32}=17.98$ & $\mu_{32}=0.69$ \\
\hline & \multicolumn{2}{|l|}{$x^{*}=(1.9,2.97,0.12)$} & $\begin{array}{l}t_{1}^{R}=1, t_{2}^{R}=0.5, t_{2}^{L}=0.5, \\
\delta=0.85, \text { and } \boldsymbol{x}^{*}=(0,3.08,1.85)\end{array}$ & $\begin{array}{l}\delta=0.91, \\
\boldsymbol{x}^{*}=(0,0.0026,4.997)\end{array}$ \\
\hline
\end{tabular}

\section{Conclusion}

Considering the advantages of the TOPSIS approach for MODM problems, this paper develops a TOPSIS approach for solving multi-level non-linear multi-objective decision-making problems. In order to obtain a compromise solution (satisfactory solution) to the MLN-MODM problems using proposed TOPSIS approach, modified formulas for the distance function from the positive ideal solution and the distance function from the negative ideal solution are proposed and modelled to include all objective functions in all levels of the MLN-MODM problems Two interactive TOPSIS algorithms for solving these problems are also proposed. The first proposed interactive TOPSIS algorithm includes the membership functions of the decision variables for each level except the lower level of the multi-level problem. These satisfactory decisions are evaluated separately by solving the corresponding single-level MODM problems. The second proposed interactive TOPSIS algorithm lexicographically solves the MODM problems of the MLN-MOLP problem by taking into consideration the decisions of the MODM problems for the upper levels. This paper also presents the algorithmic steps of the TOPSIS approach for solving single-level MODM problems of Lia et al. (1994).

An illustrative numerical example is given to demonstrate the proposed TOPSIS approach and the interactive algorithms for MLN-MODM problems. A comparison between the two proposed TOPSIS algorithms and the interactive algorithm of Osman et al. (2003) shows that the compromise solutions of first proposed algorithm and the interactive algorithm of Osman et al. 
Military Technical College

Kobry Elkobbah,

Cairo, Egypt

May 29-31,2012

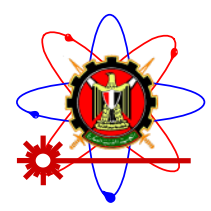

$6^{\text {th }}$ International Conference

on Mathematics and

Engineering Physics

(ICMEP-6)

(2003) are close to one another. However, it shows that the compromise solution of the second proposed algorithm is more preferred than the compromise solution of the interactive algorithm of Osman et al. (2003).

\section{References}

Abo-Sinna, M. A. (2000). Extensions of the TOPSIS for multi-objective Dynamic Programming Problems under Fuzziness. Advances in Modelling \& Analysis, B, 43 (4), 1-24.

Abo-Sinna, M. A. (2001), 'a'. A Bi-level Non-Linear Multi-objective Decision Making under Fuzziness. Journal of Operational Research Society of India, 38 (5), 484-495.

Abo-Sinna, M. A., \& Amer, A. H., (2000). Extensions of TOPSIS for multiobjective large-scale nonlinear programming problems. Applied Mathematics and Computation, 162, 243-256.

Abo-Sinna, M. A., Amer, A. H. \& Ibrahim, A. S. (2008). Extensions of TOPSIS for large scale multi-objective non-linear programming problems with block angular structure. Applied Mathematical Modelling, 32, 292-302.

Abo-Sinna, M. A., \& Baky, I. A. (2007). Interactive Balance Space Approach for Solving MultiLevel Multi-Objective Programming Problems, Information Sciences. Information Sciences, 177, 3397-3410.

Ayed, B. (1993). Bi- Level Linear programming. Computers and Operations Research, 20 (5), 485-501.

Baky, I. A. (2010). Solving multi-level multi-objective linear programming problems through fuzzy goal programming approach. Applied Mathematical Modelling, 34, 2377-2387.

Bellman, R.E., \& Zadeh, L.A. (1970). Decision-making in a fuzzy environment. Management Science, 17, 141-164.

Bialas, W. F. \& Karwan, M. H. (1984). Two Level Linear programming. Management Science, 30 (8), 1004-1020.

Chen, C.T. (2000). Extensions of the TOPSIS for group decision-making under fuzzy environment. Fuzzy Sets and Systems, 114, 1-9.

Deng, H. , Yeh, C.H. \& Willis, R. J. (2000). Inter-company comparison using modified TOPSIS with objective weights. Computers \& Operations Research, 17, 963-973,.

Hwang, C.L. \& Yoon, K. (1981). Multiple Attribute Decision Making: Methods and Applications. Berlin: Springer-Verlag.

Lai, Y-J (1996). Hierarchical optimization: a satisfactory solution. Fuzzy Sets and Systems, 77, $321-335$.

Lai, Y-J and Hwang, C. L. (1992). A New Approach to some Possibilistic Linear Programming Problems. Fuzzy Sets and Systems, 49, 121-134.

Lai, Y-J, Liu, T.-J. \& Hwang, C.L. (1994). TOPSIS for MODM. European Journal of Operational Research, 76, 486-500.

Lee, E. S. \& Shih, H.-S. (2001). Fuzzy and Multi-Level Decision Making: An Interactive Computational Approach. London: Springer.

Luhandjula, M.K. (1984). Fuzzy approaches for multiple objective linear fractional optimization. Fuzzy Sets and Systems, 13, 11-23.

Mohamed, R.H. (1997). The relationship between goal programming and fuzzy programming. Fuzzy Sets and Systems, 89, 215-222.

Moitra, B. N. \& Pal, B.B. (2002). A Fuzzy Goal Programming Approach for Solving Bilevel 
Military Technical College

Kobry Elkobbah, Cairo, Egypt May $29-31,2012$

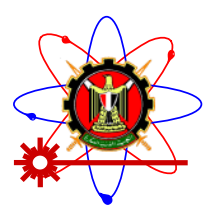

$6^{\text {th }}$ International Conference

on Mathematics and

Engineering Physics

(ICMEP-6)

Programming Problems. Proceedings of the AFSS International Conference on Fuzzy Systems. London: Springer-Verlag.

Osman, M. S., Abo-Sinna, M. A., Amer, A . H. \& Emam, O. E . (2003). Interactive DecisionMaking for Three-Level Multi-Objective Non-linear Programming Problem. The 38th Annual conference on Statistics, Computer Sciences and Operation Research, 13-16 Dec., 95110.

Osman, M. S., Abo-Sinna, M. A., Amer, A . H. \& Emam, O. E . (2004). A Multi-Level Nonlinear Multi-Objective Decision Making Under Fuzziness. Journal of Applied Mathematics and Computation, 153, 239-252.

Pramanik, S. \& Roy, T. K. (2006). Fuzzy goal programming approach to multilevel programming problems. European Journal of Operational Research, 176, 1151-1166.

Shih, H.S., Lai, Y-J., \& Lee, E.S. (1996). Fuzzy approach for multi-level programming problems, Computers and Operations Research, 23(1), 73-91.

Sinha, S. (2003). Fuzzy programming approach to multi-level programming problems. Fuzzy Sets and Systems, 136, 189-202.

Vicent, L. N. \& Calamai, P.H. (1994). Bilevel and Multilevel Programming: A Bibliography Review. Journal of Global Optimization, 5, 291-306.

Yu, P. L. \& Zeleny, M. (1975). The Set of All Non-dominated Solutions in Linear Cases and a multicriteria Simplex Method. Journal of Mathematical Analysis and Applications, 49, 430448.

Zadeh, L. A. (1965). Fuzzy sets. Information and Control, 8 (3), 338-353.

Zeleny, M. (1982). Multiple Criteria Decision Making. New York: McGraw-Hill.

Zimmermann, H-J. (1978). Fuzzy programming and linear programming with several objective functions. Fuzzy Sets and Systems, 1, 45-55.

Zimmermann, H-J. (1987). Fuzzy Sets, Decision Making, and Expert Systems. Boston: Kluwer. 